Reidt · Stickler · Glahs

Vergaberecht 



\section{Vergaberecht Kommentar}

herausgegeben von

Dr. Olaf Reidt

Rechtsanwalt und

Fachanwalt für Verwaltungsrecht, Berlin

Dr. Thomas Stickler

Rechtsanwalt und

Fachanwalt für Bau- und Architektenrecht, Leipzig

Dr. Heike Glahs

Rechtsanwältin, Bonn

bearbeitet von

Dr. Matthias Diehr

Rechtsanwalt, Berlin

Dr. Matthias Ganske

Rechtsanwalt und

Fachanwalt für Verwaltungsrecht, Bonn

Dr. Heike Glahs

Rechtsanwältin, Bonn

Dr. Olaf Reidt

Rechtsanwalt und

Fachanwalt für Verwaltungsrecht, Berlin

Dr. Thomas Stickler

Rechtsanwalt, Leipzig

3. neu bearbeitete Auflage

2011

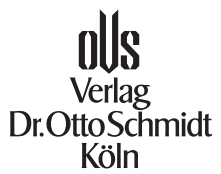




\section{Zitierempfehlung:}

Bearbeiter in Reidt/Stickler/Glahs, Vergaberecht

Kommentar, 3. Aufl. 2011, § ... GWB/VgV

Bibliografische Information

der Deutschen Nationalbibliothek

Die Deutsche Nationalbibliothek verzeichnet diese

Publikation in der Deutschen Nationalbibliografie; detaillierte bibliografische Daten sind im Internet über http://dnb.d-nb.de abrufbar.

Verlag Dr. Otto Schmidt KG

Gustav-Heinemann-Ufer 58, 50968 Köln

Tel. 02 21/9 37 38-01, Fax 02 21/9 37 38-943

info@otto-schmidt.de

www.otto-schmidt.de

ISBN 978-3-504-40073-6

(C)2011 by Verlag Dr. Otto Schmidt KG, Köln

Das Werk einschließlich aller seiner Teile ist urheberrechtlich geschützt. Jede Verwertung, die nicht ausdrücklich vom Urheberrechtsgesetz zugelassen ist, bedarf der vorherigen Zustimmung des Verlages. Das gilt insbesondere für Vervielfältigungen, Bearbeitungen, Übersetzungen, Mikroverfilmungen und die Einspeicherung und Verarbeitung in elektronischen Systemen.

Das verwendete Papier ist aus chlorfrei gebleichten Rohstoffen hergestellt, holz- und säurefrei, alterungsbeständig und umweltfreundlich.

Einbandgestaltung: Jan P. Lichtenford, Mettmann

Satz: Schäper, Bonn

Druck und Verarbeitung: Kösel, Krugzell

Printed in Germany 